\title{
miR-101 Promotes Breast Cancer Cell Apoptosis by Targeting Janus Kinase 2
}

\author{
Lu Wang $^{a}$ Linqiang Lib Rui Guo Xuelian Lia Ying Lu ${ }^{a}$ Xiaoxiang Guan ${ }^{a}$ \\ Samuel Chege Gitau ${ }^{\mathrm{a}}$ Leimin Wang ${ }^{\mathrm{a}}$ Chaoqian $\mathrm{Xu}^{\mathrm{a}}$ Baofeng Yang ${ }^{\mathrm{a}}$ Hongli Shan $^{\mathrm{a}}$ \\ aDepartment of Pharmacology (State-Province Key Laboratories of Biomedicine- Pharmaceutics of \\ China, Key Laboratory of Cardiovascular Research, Ministry of Education), Harbin Medical University, \\ ${ }^{b}$ Key Laboratory of Hepatosplenic Surgery, Department of General Surgery, The First Affiliated Hospital \\ of Harbin Medical University, Harbin, P. R. China
}

\section{Key Words}

Apoptosis • Breast cancer $•$ Jak2 $・$ miR-101

\begin{abstract}
Aims: microRNA-101 (miR-101) is down-regulated in several cancers. In this study, we explored the effects of dysregulated miR-101 on breast cancer cells and the underlying mechanisms. Methods: miR-101 level was quantified by real-time RT-PCR. Cell viability was analyzed by MTT assay. Apoptosis was detected by flow cytometry and TUNEL assay. Moreover, the level of protein expression was determined by Western blot. Results: miR-101 level was markedly reduced in both the human breast cancer samples and cultured breast cancer cell lines (MCF7, MDA-MB-231). Overexpression of miR-101 inhibited the proliferation and promoted the apoptosis in cultured MCF-7 and MDA-MB-231 cells, which were reversed by co-transfection of AMO-101, the inhibitor of miR-101. We validated Janus kinase 2 (Jak2) as a direct target of miR-101. Knockdown of Jak2 induced apoptosis in cultured breast cancer cells. Moreover, the level of miR-101 is negatively correlated with Jak2 in breast cancer tissues and cell lines. Conclusions: miR-101 suppressed proliferation and promoted apoptosis in breast cancer cells by targeting Jak2. These findings indicate that manipulation of miR-101 expression may represent a novel therapeutic strategy in the treatment of breast cancer.
\end{abstract}

Copyright (C) 2014 S. Karger AG, Basel

\section{Introduction}

Breast cancer is the most common malignancy in women, accounting for $27 \%$ of all female cancers. Although various therapeutic strategies have been employed in treating breast cancer clinically, the clinical outcome remains far from satisfied. In 2008, breast

Lu Wang and Linqiang Li contributed equally to this work.

Hongli Shan Harbin Medical University

No.157 Baojian Road, Harbin, Heilongjiang Province, 150081 (P. R. China)

Tel. +86-451-86671354, Fax +86-451-86671354, E-Mail shanhongli72@aliyun.com 
cancer caused 458,503 deaths worldwide (13.7\% of cancer deaths in women) [1]. Numerous efforts have been made to elucidate the mechanisms of breast cancer, and to develop novel therapeutic strategies. Apoptosis serves as a natural barrier to cancer development. Many studies have focused on the molecular and/or cellular mechanisms that underlie tumor formation and progression associated with apoptosis [2].

Janus kinase 2 (Jak2), a member of the JAK family of protein tyrosine kinases (PTKs), is a crucial intracellular mediator of cytokine and hormone signaling and is ubiquitously expressed in virtually every cell type. A growing body of evidence demonstrates that the activation of the Jak2 signaling pathway is required for the growth of solid tumor cells. Jak2 was reported to be overexpressed in breast cancer [3,4], which promotes malignant cell survival and growth by modulating cell apoptosis partly through the up-regulation of Bcl-2 family members, such as mcl-1, Bcl-xl, and Bcl-2 [5, 6].

MicroRNAs (miRNAs) are a class of small, $\sim 22$-nucleotides-long, non-coding RNAs that are believed to regulate the expression of up to $30 \%$ of human genes by binding to the $3^{\prime}$ UTR of mRNAs [7, 8]. A given miRNA may have multiple different messenger RNA (mRNA) targets. An increasing body of evidence indicates that miRNAs are important regulatory genes in mammals and are significantly involved in the development of many types of human diseases. The ectopic expression of miRNAs is closely associated with carcinogenesis and cancer progression $[9,10]$. miR-21 and miR-657, which act as proto-oncogenes, are reported to promote cancer progression $[11,12]$, whereas miR-29 and miR-145 are shown to be tumor-suppressor genes $[13,14]$. The down-regulation of miR-101 has been reported in various solid tumors, such as colorectal cancer and hepatoma $[15,16]$. The down-regulation of miR-101 and the increased expression of EZH2 (enhancer of zeste homolog 2) was first revealed in prostate cancer. Since then, the effect of miR-101 has been confirmed in many cancers, including breast cancer [17]. This study was designed to investigate the potential molecular mechanisms of miR-101 mediated anti-proliferative and pro-apoptotic effects in breast cancer cells.

\section{Materials and Methods}

\section{Human tissue samples}

Human breast cancer tissues were provided by the Third Affiliated Hospital of Harbin Medical University after approval was obtained from the University's Ethics Committee on the Use of Human Samples. The tissues were obtained from 20 individuals undergoing surgery due to invasive ductal carcinoma or invasive lobular carcinoma. The sampled tissues were immediately snap-frozen in liquid nitrogen and stored at $-80^{\circ} \mathrm{C}$.

\section{Cell culture}

Human embryonic kidney cells (HEK293; ATCC, Manassas, VA, USA) were cultured in Dulbecco's Modified Eagle Medium (DMEM) containing 10\% fetal bovine serum (FBS; Hyclone, USA). The human breast cancer cell lines MCF-7 and MD-MB-231 were purchased from Cell Bank of the Chinese Academy of Sciences (Shanghai, China) and cultured in RPMI 1640 (Hyclone, USA) supplemented with 10\% FBS and $100 \mathrm{mg} /$ $\mathrm{ml}$ penicillin/streptomycin at $37^{\circ} \mathrm{C}$ in an incubator composed of $95 \%$ air and $5 \% \mathrm{CO}_{2}$. MCF-10A cell line, a non-tumorigenic epithelial cell line, was cultured in DMEM/F12(1:1) (Hyclone, USA) supplemented with $5 \%$ horse serum, $10 \mathrm{ug} / \mathrm{ml}$ insulin, $20 \mathrm{ng} / \mathrm{ml} \mathrm{EGF,} 100 \mathrm{ng} / \mathrm{ml}$ cholera toxin and $0.5 \mu \mathrm{g} / \mathrm{ml}$ hydrocortisone at $37^{\circ} \mathrm{C}$ in an incubator composed of $95 \%$ air and 5\% CO2. MCF-10A was purchased from Cell Resource Center (Beijing, China).

\section{miRNAs and siRNA transfection}

Negative control (NC), miR-101, and AMO-101 (anti-miR-101 oligonucleotide) were synthesized by GenePharma (Shanghai, China). miR-101 was non-chemically modified as defined in miRBase (http://www. mirbase.org/). Jak2 siRNA was purchased from Cell Signaling Technology. The cells were transfected with NC, miR-101, AMO-101, or siRNA using Lipofectamine 2000 (Invitrogen, USA) following the manufacturer's protocol. 


\section{Real-time PCR}

The total RNA from the human tissues and cell lines was extracted using Trizol (Invitrogen, USA). The levels of miR-101 and Jak2 mRNA were quantified using the mirVana qRT-PCR (quantitative real-time PCR) miRNA Detection Kit (Ambion, USA) in conjunction with real-time PCR with SYBR Green I (Applied Biosystems, USA), as described in detail in a previous study [18]. The qRT-PCR was performed on an ABI Prism ${ }^{\circledR} 7500$ fast thermocycler (Applied Biosystems) for 40 cycles. The following Jak2 primers were used for PCR detection: 5'-GGGAGGTGGTCGCTGTAAAA-3' (forward); 5'-ACCAGCACTGTAGCACACTC-3' (reverse). The relative expression levels of miR-101 and Jak2 were calculated through normalization to their internal controls, U6 and GAPDH, respectively. The relative expression intensity values were calculated as $2^{-\Delta \Delta C t}$.

\section{MTT assay}

The cells were cultured in 96-well plates, and each well was seeded with $4 \times 10^{3}$ cells. After transfection with $50 \mathrm{nM}$ microRNA and negative control for 24, 48, and 72 hours, the viability of the cancer cells was detected with 3-(4,5-dimethylthiazol-2-yl)-2,5-diphenyl tetrazolium bromide (MTT; Roche; Switzerland). $20 \mu \mathrm{l}$ of MTT solution ( $5 \mathrm{mg} / \mathrm{ml}$ ) was added to each well, and the mixtures were incubated for $4 \mathrm{~h}$ at $37^{\circ} \mathrm{C}$. Then, $150 \mu \mathrm{l}$ of dimethyl sulfoxide (DMSO) was added to the wells. The absorbance was measured using an ELISA plate reader at $490 \mathrm{~nm}$. A high absorbance indicated a greater viability.

\section{Flow cytometry}

The cancer cells were transfected for $48 \mathrm{~h}$ then collected and washed twice with cold PBS (phosphate buffered saline). The cells were resuspended in $500 \mu \mathrm{l}$ of binding buffer at a concentration of $10^{6}$ cells/ $\mathrm{ml}$ and then mixed with $10 \mu \mathrm{l}$ of Annexin V (Beyotime Institute of Biotechnology, China) for 15 min in the dark at room temperature (RT). Then $5 \mu$ of PI (Beyotime Institute of Biotechnology, China) was added to the cells. After incubation for $5 \mathrm{~min}$ in the dark at RT, the samples were analyzed using a FACSAria flow cytometry (BD Biosciences, San Jose, CA, USA).

\section{TUNEL assay}

The TUNEL assay was performed according to the manufacturer's protocol (In Situ Cell Death Detection Kit, POD, Roche, Switzerland). Briefly, the cells were fixed in 4\% paraformaldehyde in PBS, washed three times with PBS, and washed with $3 \% \mathrm{H}_{2} \mathrm{O}_{2}$ in methanol for 10 min at RT. After incubating with $0.1 \%$ Triton $\mathrm{X}-100$ in $0.1 \%$ sodium citrate for $2 \mathrm{~min}$ on ice, the cells were incubated with the TUNEL reaction mixture for $1 \mathrm{~h}$ and then with DAPI for $5 \mathrm{~min}$ in the dark at RT. Fluorescence microscope (Eclipse 80I, Nikon, Japan) were used for data analysis.

\section{Caspase-3 activity assay}

The activity of caspase- 3 was determined using the caspase- 3 activity kit (Beyotime Institute of Biotechnology, China) according to the manufacturer's protocol. In brief, the assays were performed in 96well microtitre plates. Ten microliters of the cell lysate proteins of each sample were incubated in $80 \mu \mathrm{l}$ of reaction buffer (1\% NP-40, $20 \mathrm{mmol} / \mathrm{L}$ Tris- $\mathrm{HCl}$ [pH 7.5], $137 \mathrm{mmol} / \mathrm{L} \mathrm{NaCl}$, and 10\% glycerol) containing $10 \mu \mathrm{L}$ of caspase-3 substrate ( $2 \mathrm{mmol} / \mathrm{l} \mathrm{Ac-DEVD-pNA})$ at $37^{\circ} \mathrm{C}$ for $4 \mathrm{~h}$. The absorbance of the samples was measured using an ELISA reader at a wavelength of $405 \mathrm{~nm}$.

\section{Western blot}

The Western blot analysis was conducted as described elsewhere [18]. The total protein was extracted from the cancer cells samples. Equal amounts of protein were loaded on a 10\% SDS-PAGE gel. The lysates were resolved by electrophoresis ( $70 \mathrm{~V}$ for $30 \mathrm{~min}$ and $100 \mathrm{~V}$ for $1.5 \mathrm{~h}$ ) and transferred onto NC membranes (nitrocellulose membrane, Bio-Rad, USA). After blocking in 5\% nonfat milk for $2 \mathrm{~h}$ at room temperature, the membranes were incubated with anti-Jak2 (1:1000, Cell Signaling Technology, USA) or anti-phosphoJak2 (1:1000, Cell Signaling Technology, USA), anti-Bax, anti-caspase-3 (1:200, Santa, USA), and anti-Bcl-2 (1:200, Santa, USA). GAPDH (glyceraldehyde-3-phosphate) was used as an internal control to ensure equal protein loading. The Western blot bands were quantified using the Odyssey v1.2 software (Infrared Imaging System LI-COR Biosciences) by measuring the band intensity (Area $\times$ OD, Optical Density) for each group and normalizing this intensity by that of GAPDH. The final results are expressed as fold changes by normalizing the data to the control values. 
A

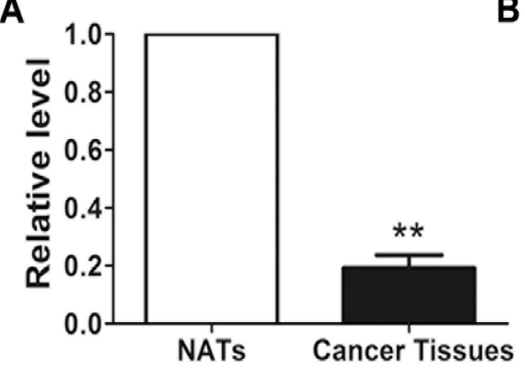

B

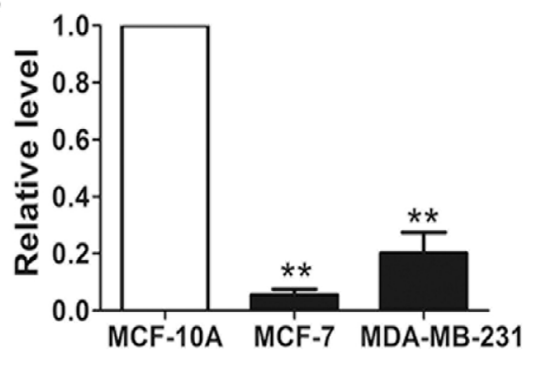

Fig. 1. miR-101 was down-regulated in human breast cancer tissues and cell lines. (A) The level of miR-101 was decreased in breast cancer tissues compared with NATs (control; refer to the normal adjacent tissues); ${ }^{* *} \mathrm{p}<0.01$ vs. NATs. (B) miR-101 was absent in MCF-7 and MDA-MB-231 cells compared with MCF-10A (control); $\mathrm{n}=4 *{ }^{* *} \mathrm{p}<0.01$ vs. MCF-10A.

\section{Luciferase assay}

To generate reporter vectors bearing miRNA-binding sites, the $3^{\prime}$-untranslated region (3'-UTR) of Jak2 and its mutation type were synthesized by Sangon (Shanghai, China). The construct was inserted into multiple cloning sites downstream of the luciferase gene (SacI and HindIII sites) in the pMIR-REPORT luciferase miRNA expression reporter vector (Ambion, USA). For the luciferase assay, $0.1 \mu \mathrm{g}$ of luciferase reporters containing 3'-UTR were cotransfected with miR-101, or both miR-101 and AMO-101 into HEK293 cells using lipofectamine 2000 (Invitrogen, USA). As an internal control, $10 \mathrm{ng}$ of renilla luciferase reporters were also included. $48 \mathrm{~h}$ after transfection, the cells were collected and dual luciferase activities were measured by a luminometer according to the manufacturer's instructions [19].

\section{Statistical analysis}

All the data are presented as means \pm SEM. The statistical comparisons among multiple groups were performed using analysis of variance (ANOVA). If significant effects were indicated by ANOVA, a t-test using the Bonferroni correction or a Dunnett's test were used to evaluate the significance of the differences between the individual means. Otherwise, the data were compared by Student's t-test. A two-tailed difference with $\mathrm{p}<0.05$ was considered statistically significant. The data were analyzed using GraphPad Prism 5.0 and SPSS 14.0 .

\section{Results}

MiR-101 was significantly down-regulated in human breast cancer tissues and cell lines

To evaluate the level of miR-101 in breast cancer, qRT-PCR was used to quantify its expression in 20 couples of breast cancer tissues and normal adjacent tissues (NATs). miR101 was significantly decreased in breast cancer specimens compared with NATs (Fig. 1A). Furthermore, the expression of miR-101 in breast cancer cell lines (MCF-7 and MDAMB-231) was compared with breast epithelial cell line MCF-10A (Fig. 1B). miR-101 was also significantly down-regulated in breast cancer cells.

\section{Effect of miR-101 on breast cancer cells}

The successful transfection of miR-101 was shown in Fig.2A. We then explored whether the deregulated miR-101 will produce any effects on the proliferation and apoptosis of breast cancer cells. An MTT assay was performed to detect the viability of MCF-7 and MDA-MB-231 cells after transfection with $50 \mathrm{nM}$ miR-101 for 24,48 , and $72 \mathrm{~h}$. The data showed that the viability of cells was significantly decreased in the miR-101 group compared with the NC (control) group, with a higher inhibitory effect observed $48 \mathrm{~h}$ after miR-101 treatment (Fig. 2B). 


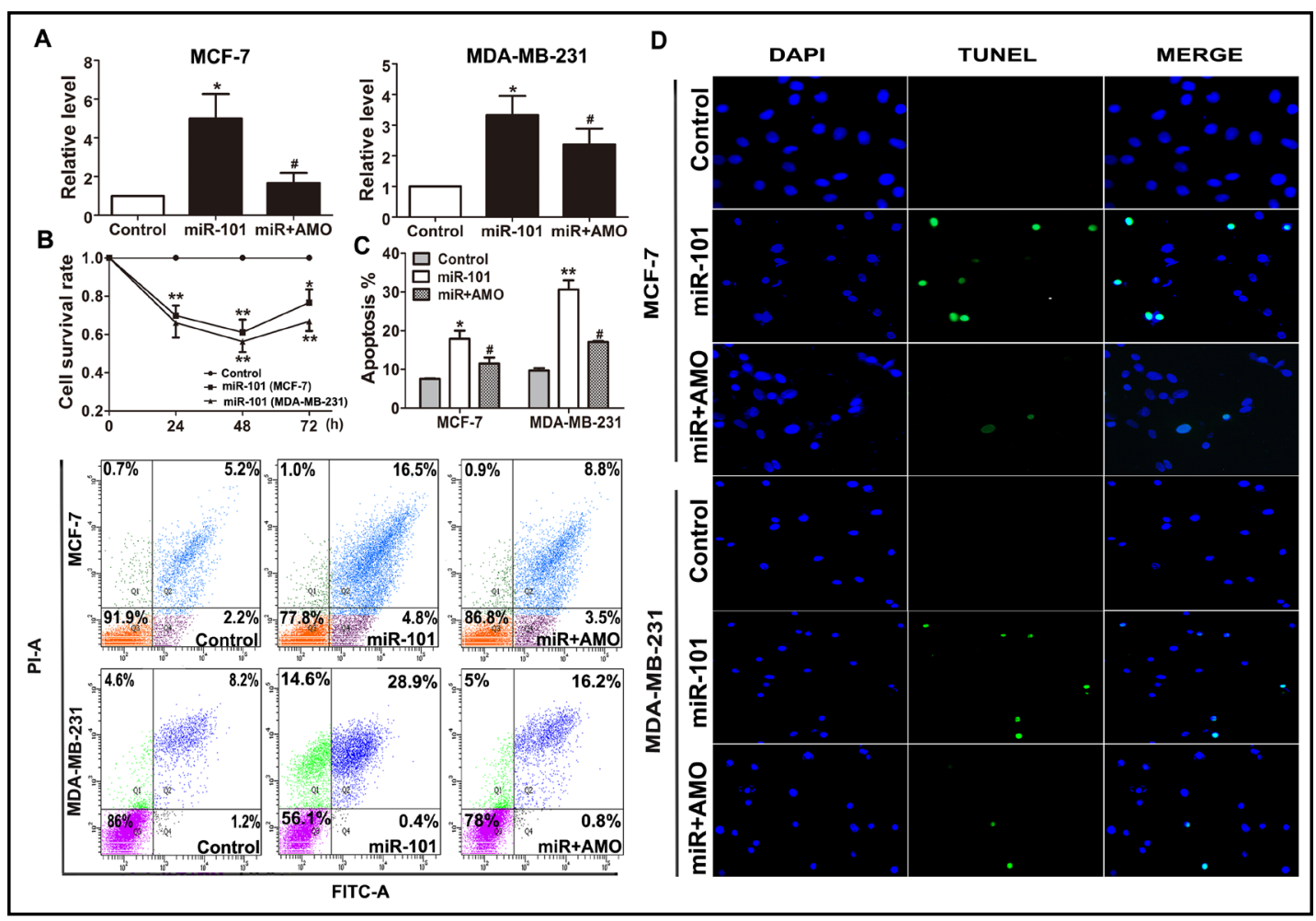

Fig. 2. miR-101 regulates the viability and apoptosis of breast cancer cells. (A) miR-101 level after transfection. ${ }^{*} \mathrm{p}<0.05$ vs. Control group; $\# \mathrm{p}<0.05$ vs. miR-101 group. (B) miR-101 decreased the viability of breast cancer cells by MTT assay. The cell viability was significantly decreased after transfection with miR-101 for $48 \mathrm{~h} ; \mathrm{n}=6^{*} \mathrm{p}<0.05$ and ${ }^{* *} \mathrm{p}<0.01$ vs. Control (negative control) group. (C) Apoptosis of breast cancer cells after miR-101 transfection for $48 \mathrm{~h}$ by flow cytometry. Data are presented as means \pm SEM of three separate experiments; ${ }^{*} \mathrm{p}<0.05$ and ${ }^{* *} \mathrm{p}<0.01$ vs. Control group; $\# \mathrm{p}<0.05$ vs. miR-101 group. (D) Apoptosis of breast cancer cells after miR-101 transfection for $48 \mathrm{~h}$ by TUNEL staining. Apoptotic cells are green, and the nuclei are stained blue with DAPI.

Annexin V and PI double staining and flow cytometric analyses were then performed to detect the apoptosis induced by miR-101 in MCF-7 and MDA-MB-231 cells. The apoptotic cells (Annexin V-positive) were significantly increased after miR-101 treatment, which was obviously reversed by the co-transfection of AMO-101 (Fig. 2C). Moreover, the TUNEL assays also revealed that the number of apoptotic positive cells was increased in cultured breast cancer cells transfected with miR-101 (Fig. 2D). These data indicated that miR-101 is antiproliferative and pro-apoptotic in breast cancer cells.

\section{Jak2 is a direct target of miR-101}

To elucidate the molecular mechanism by which miR-101 promotes breast cancer cell apoptosis, a bioinformatic analysis was performed to identify the potential target genes. Jak2 was predicted to be a potential target of miR-101 according to TargetScan database. We then investigated the regulation of miR-101 on Jak2 expression. We found overexpression of miR101 significantly inhibited both the mRNA (Fig. 3A) and protein (Fig. 3B) expression of Jak2, which can be abolished by co-transfection of AMO-101. Moreover, the relative level of the phosphorylated form of Jak2 (p-Jak2) was consistent with the total Jak2 protein (Fig. 3B).

To further validate whether Jak2 is a direct target of miR-101, luciferase reporter constructs containing a segment of the 3'-UTR of Jak2 (Jak2) or a mutated 3'-UTR of Jak2, which contained a mutated seed sequence (Mut-Jak2), were generated (Fig. 3C). The constructs were co-transfected with miR-101 into HEK293 cells. Co-transfection of miR101 strongly inhibited the luciferase activity of the reporter construct containing the 3'-UTR 
A

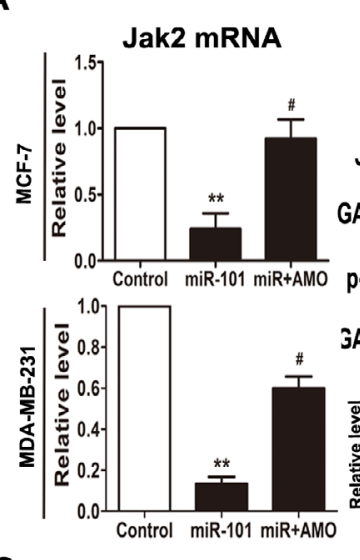

B

C
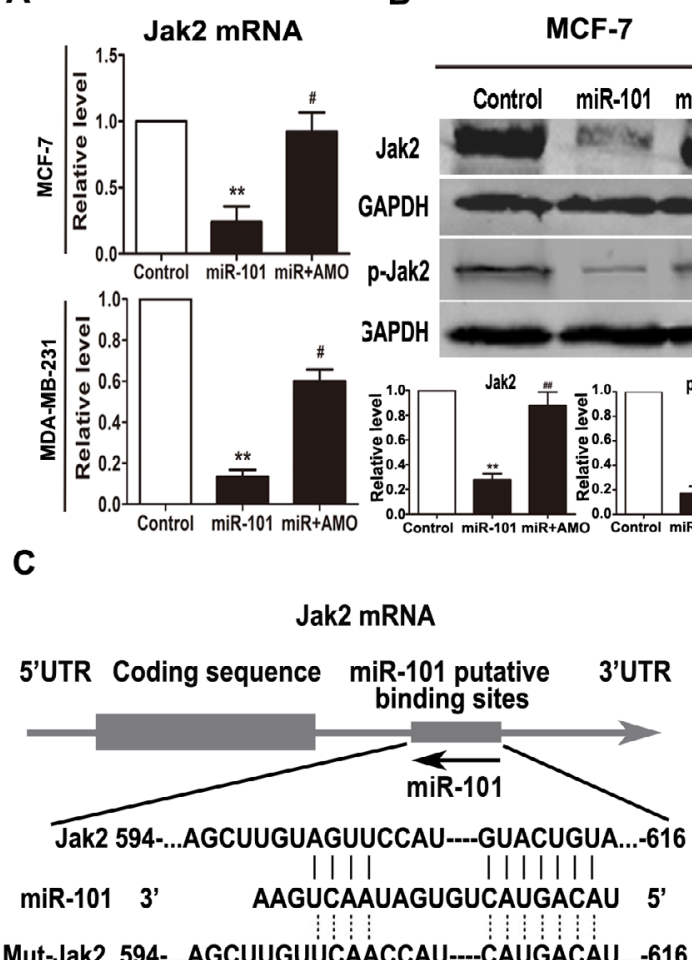

Mut-Jak2 594-...AGCUUGUÚCAACCAU---.CAUGACAU...-616
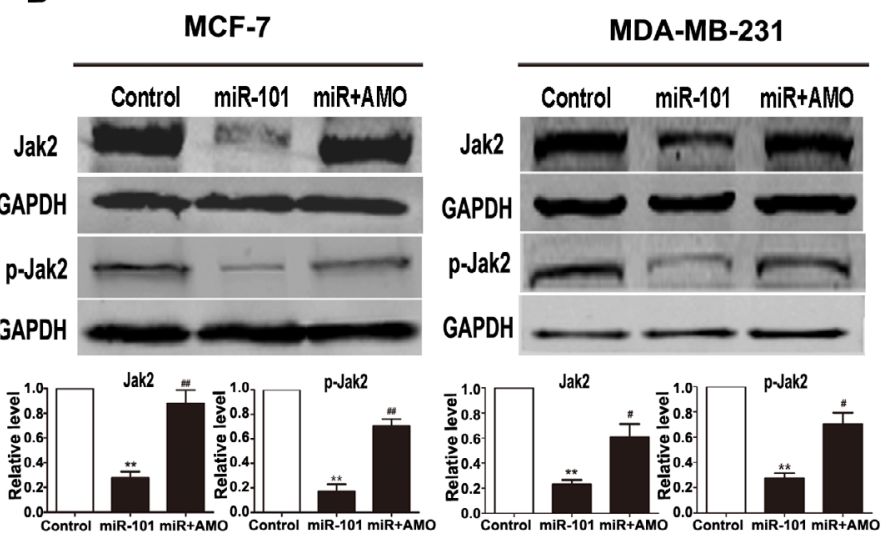

D

Fig. 3. Jak2 is a direct target of miR-101. (A) mRNA level of Jak2 was evaluated by real-time PCR $48 \mathrm{~h}$ after miR-101 transfection in MCF-7 and MDA-MB-231 cells. $n=4{ }^{* *} \mathrm{p}<0.01$ vs. Control group; \#P<0.05 vs. miR101 group. (B) Protein level of Jak2 and p-Jak2 in breast cancer cell lines $48 \mathrm{~h}$ after miR-1 transfection. $\mathrm{n}=6$ for Jak2 (MCF-7), n=4 for Jak2 (MDA-MB-231), n=4 for p-Jak2 (MCF-7), and n=3 for p-Jak2 (MDA-MB-231). ${ }^{* *} \mathrm{p}<0.01$ vs. Control group; $\# \mathrm{p}<0.05$ and $\# \# \mathrm{p}<0.01$ vs. miR-101 group. (C) The potential interaction between miR-101 and two putative binding sites in the Jak2 3 '-UTR predicted by TargetScan. The mutant sequences are equivalent to the wild-type ones with the exception of mutations at the $3^{\prime}$ end of the target site. (D) The luciferase activities were analyzed in HEK293 cells $48 \mathrm{~h}$ after transfection. The data are presented as the means \pm SEM of three separate experiments, ${ }^{*} \mathrm{p}<0.05$ and $\# \mathrm{p}<0.05$.

segment of Jak2, whereas no effect was observed in the corresponding mutated construct (Fig. 3D), indicating that Jak2 is a direct target of miR-101.

The expression of Jak2 is negatively correlated with miR-101 level in breast cancer tissues and cell lines

We examined the expression of Jak2 in breast cancer tissues and cell lines. We found that Jak2 is over-expressed in breast cancer tissues and breast cancer cell lines (MCF-7 and MDAMB-231) than in NATs and MCF-10A cell line, respectively. The same qualitative alteration was observed in terms of the expression of phosphorylated Jak2 (Fig. 4). We then analyzed the correlation between Jak2 protein expression and miR-101 in breast cancer tissues and cell lines. These data indicated that the expression of miR-101 and Jak2 is negatively correlated in breast cancer tissues and cell lines (Fig. 1 and 4).

miR-101 regulates apoptosis by targeting Jak2 in breast cancer cells

The influence of miR-101 on the expression of apoptosis-related proteins Bcl-2, Bax and caspase- 3 was detected. Transfection of miR-101 for $48 \mathrm{~h}$ significantly inhibited the expression of Bcl-2, while increased the expression of Bax and caspase- 3 in breast cancer 
A

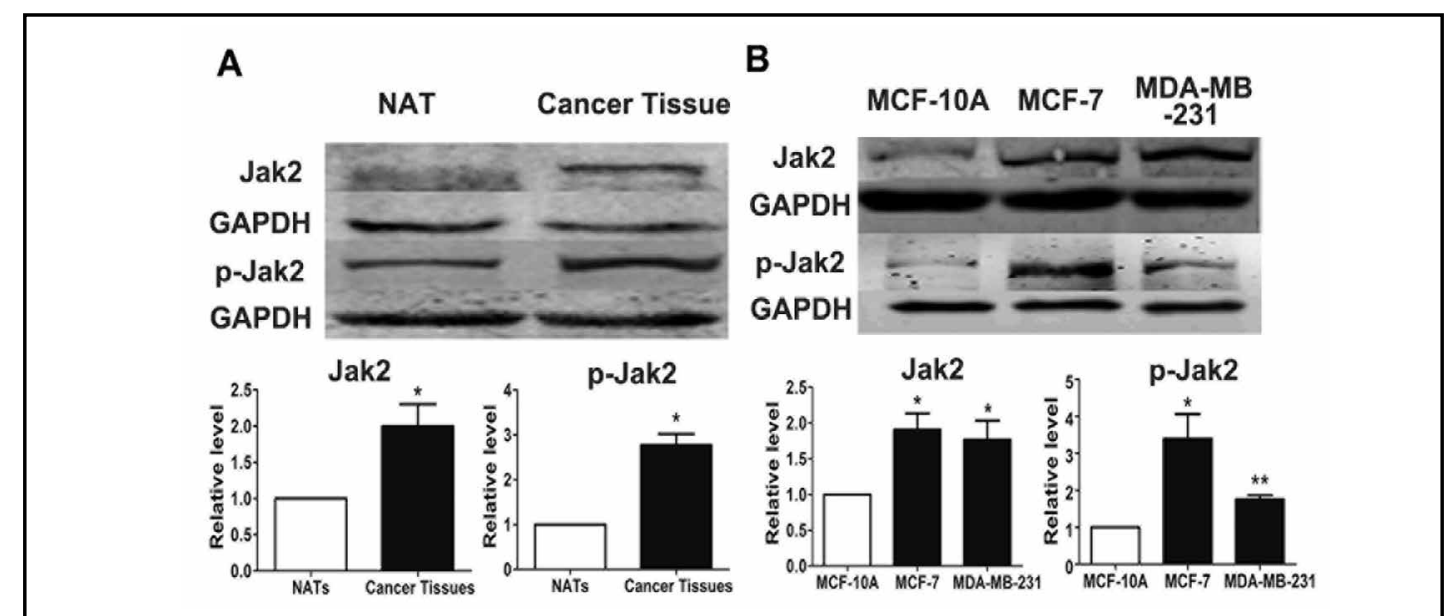

B

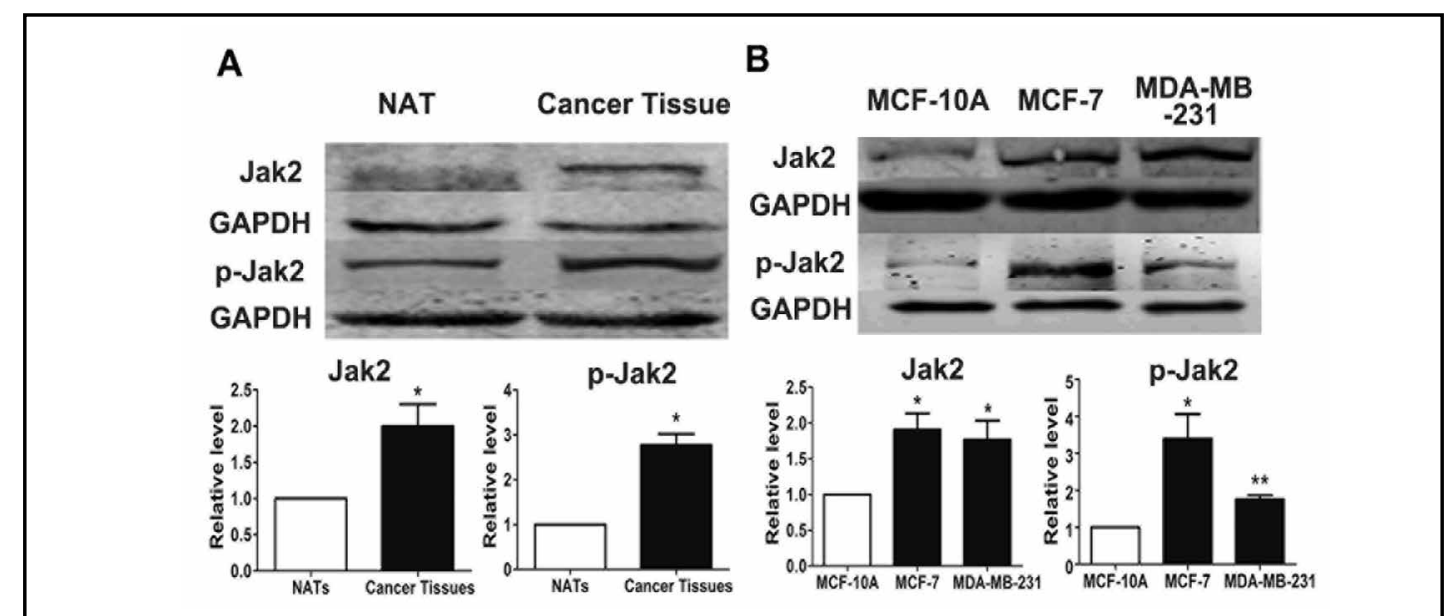

Fig. 4. Negative correlation between miR-101 and Jak2 in huamn breast cancer tissues and cell lines. (A) Expression of Jak2 and p-Jak2 in breast cancer tissues. Data were expressed as the mean \pm SEM. $n=4$ for Jak2; $n=4$ for $\mathrm{p}$-Jak2. ${ }^{*} \mathrm{p}<0.05$ vs. NATs. (B) Jak2 and p-Jak2 were up-regulated significantly in MCF-7 and MDA-MB-231 compared with MCF-10A; $n=6$ for Jak2 and $n=6$ for $p-J a k 2 ~ * p<0.05$ and ${ }^{* *} p<0.01$ vs. MCF-10A.

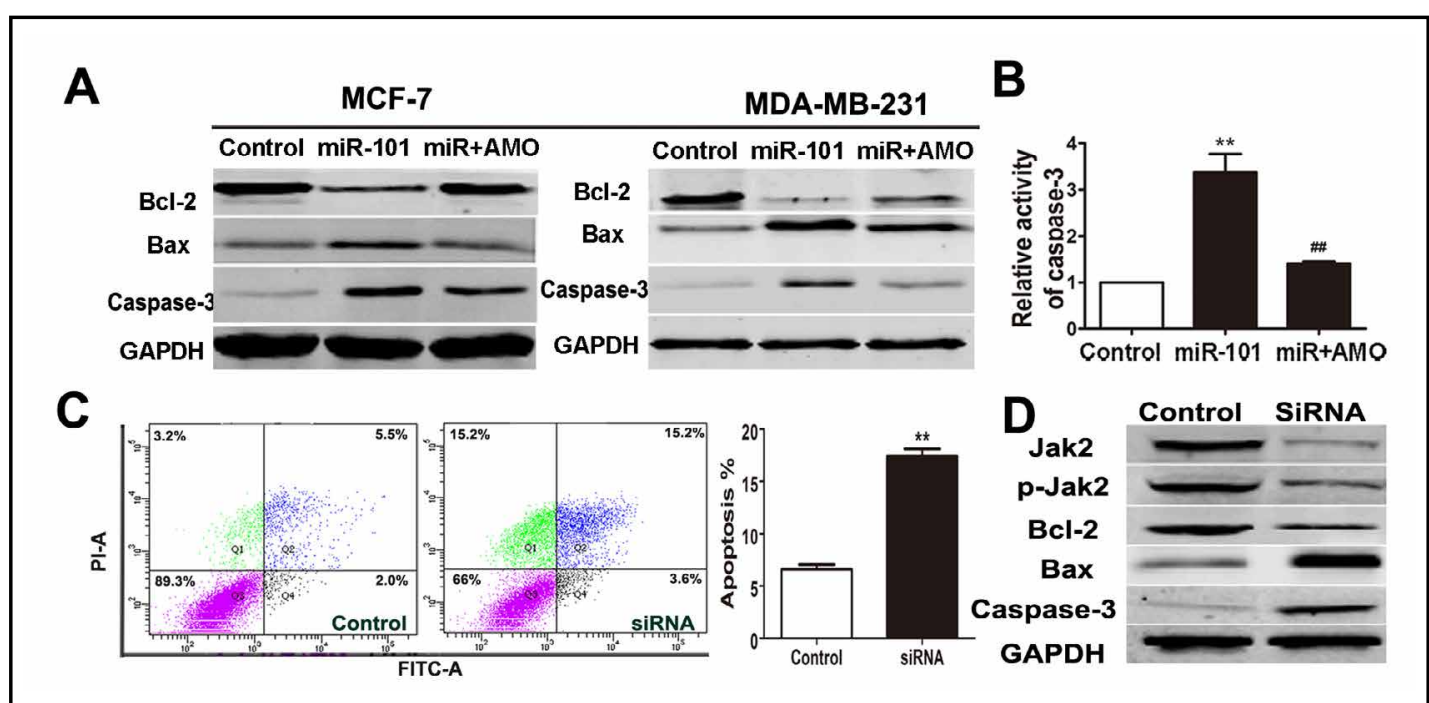

Fig. 5. miR-101 regulates apoptosis by targeting Jak2 in breast cancer cells. (A) Protein levels of Bcl-2, Bax, and caspase-3 in MCF-7 and MDA-MB-231 cells after treated with miR-101 for 48 h. (B) The activity of caspase-3 in MCF-7 cells was analyzed using an apoptosis ELISA kit after transfection for $48 \mathrm{~h}$. The quantification of DNA fragmentation was expressed as optical density values. $n=5{ }^{* *} \mathrm{p}<0.01$ vs. Control group; \#\#p<0.01 vs. miR-101 group. (C) MCF-7 cell apoptosis detected by flow cytometry $48 \mathrm{~h}$ after Jak2 siRNA transfection, Data are presented as the means \pm SEM of three separate experiments; ${ }^{* *} \mathrm{p}<0.01$ vs. Control group. (D) Jak2, p-Jak2, Bcl-2, Bax, and caspase-3 proteins were detected after transfection of Jak2 siRNA.

cells. Co-transfection of AMO-101 with miR-101 canceled this effect (Fig. 5A). miR-101 also significantly increased the activity of caspase-3 (Fig. 5B).

Subsequently, the role of Jak2 in apoptosis of MCF-7 cells was tested. Transfection with Jak2 siRNA promoted MCF-7 cell apoptosis (Fig. 5C) and down-regulated the expression of Jak2 and p-Jak2 (Fig. 5D), indicating that Jak2 suppression is pro-apoptotic. 
Wang et al.: miR-101 Inhibits Breast Cancer Cells

\section{Discussion}

In this study, we showed that miR-101 is down-regulated in human breast cancer samples, which is consistent with that of a previous study [20]. miR-101 expression was also reduced in the breast cancer cell lines MCF-7 and MDA-MB-231, which are estrogen receptorpositive and triple-negative (estrogen receptor, progesterone receptor, and ERBB2) breast cancer cells, respectively. We validated Jak2 as the direct target of miR-101, which accounts for the pro-apoptotic effects of miR-101 in breast cancer cells.

The discovery of miRNAs has opened a new avenue for both the diagnosis and treatment of cancers. Increasing evidence from experimental studies has demonstrated that miRNAs play crucial roles in the regulation of tumor proliferation, metastasis, and invasion and may offer potential therapeutic targets for cancer intervention and treatment [21]. miR-101 has been demonstrated to be one of the anti-tumor miRNAs. It was shown to be down-regulated in human gastric, liver, and pancreatic cancers. In addition, a lower expression of miR-101 is associated with poorer prognosis. A functional analysis has demonstrated that reduced expression of miR-101 promotes cancer proliferation and suppresses apoptosis by directly targeting EZH2 [22-24]. Another study showed that overexpression of miR-101 in gastric cancer cell lines inhibits cell proliferation and induces apoptosis in vitro, and inhibits tumor growth in vivo [25]. In this study, we explored the role of miR-101 in breast cancer. Consistently, we observed the down-regulation of miR-101 in human breast cancer samples and cell lines, and its pro-apoptotic activity in breast cancer.

Although recent studies also have shown that miR-101 is down-regulated in breast cancer and produced anti-tumor effects $[17,26]$, the mechanisms through which miR101 affects cell growth have not been fully elucidated. Previous studies mainly focused on its regulation of the oncogene EZH2 in breast cancer. In other types of cancers, miR-101 regulates the MAPK, Akt, and Wnt/ $\beta$-Catenin pathways to exert its anti-tumor action [15, $27,28]$. In this study, we demonstrated the important role of Jak2 in mediating miR-101induced apoptosis. Jak2 is a non-receptor tyrosine kinase that regulates several cellular processes by inducing cytoplasmic signaling cascades. Jak2 is involved in the proliferation, angiogenesis, immune evasion, and anti-apoptosis of cancer cells, and signal transducers and activators of Jak2 are constitutively activated in many human solid tumors, Inhibition of Jak2 was consider as a novel strategy in developing anticancer agents [29, 30, 31]. It is well accepted that Jak2 is overexpressed in breast cancer, which deteriorates breast cancer and promotes cell survival [4]. In the present study, we demonstrated the ability of miR-101 to activate apoptosis through the regulation of Jak2 in breast cancer cells. Down-regulation of Jak2 at both mRNA and protein levels was observed in the miR-101-transfected cells, which was alleviated by co-transfection of AM0-101.

We found that miR-101 suppresses Jak2 expression by directly interacting with the 3'-UTR of Jak2. This finding is also, to some extent, supported by the negative correlation between miR-101 and Jak2 in breast cancer tissues and cancer cell lines. The downstream signaling proteins Bcl-2, Bax, and caspase- 3 of Jak2 were examined to further confirm the key role of Jak2 pathway in miR-101 induced apoptosis of breast cancer cells. Bcl-2 is an inhibitor of apoptosis and acts mainly by binding to and thereby suppressing the proapoptotic triggering protein Bax. Caspase-3 plays a central role in the execution phase of cell apoptosis. In this study we found the protein level of Bcl-2 decreased, while Bax and caspase-3 increased in MCF-7 and MDA-MB-231 cells treated with miR-101.

Although our study identified miR-101 as an important molecule in the control of cell apoptosis, it should be noted that the mechanisms by which miR-101 expression is reduced in breast cancer cells have not yet been determined. Additionally, we can not exclude the involvement of other mechanisms that may mediate the pro-apoptotic property of miR-101. Moreover, the relative importance of miR-101 to other tumor-regulating miRNAs in the development of cancer is also currently unclear.

Collectively, the present study demonstrated that miR-101 induces breast cancer cell apoptosis through the inhibition of Jak2 pathway. Our findings highlight the potential of miR-101 as a prognosis marker and therapeutic target for breast cancer 
Wang et al.: miR-101 Inhibits Breast Cancer Cells

\section{Acknowledgments}

This work was supported in part by the National Basic Research Program of China (973 Program; 2013CB531104), the Funds for Creative Research Groups (81121003) of the National Natural Science Foundation of China, the National Nature Science Foundation of China (No31001434), and the Postgraduate Innovation Fund of Heilongjiang Province (YJSCX2012-245HLJ).

\section{Disclosure Statement}

The authors have no conflicts of interest.

\section{References}

1 Jemal A, Bray F, Center MM, Ferlay J, Ward E, Forman D: Global cancer statistics. CA Cancer J Clin 2011;61:69-90.

- Hanahan D, Weinberg RA: Hallmarks of cancer: the next generation. Cell 2011;144:646-674.

3 Harry BL, Eckhardt SG, Jimeno A: JAK2 inhibition for the treatment of hematologic and solid malignancies. Expert Opin Investig Drugs 2012;21:637-655.

4 Behera R, Kumar V, Lohite K, Karnik S, Kundu GC: Activation of JAK2/STAT3 signaling by osteopontin promotes tumor growth in human breast cancer cells. Carcinogenesis 2010;31:192-200.

5 Sakai I, Kraft AS: The kinase domain of Jak2 mediates induction of Bcl-2 and delays cell death in hematopoietic cells. J Biol Chem 1997;272:12350-12358.

-6 Verma A, Kambhampati S, Parmar S, Platanias LC: Jak family of kinases in cancer. Cancer and Metastasis Reviews 2003;22:423-434.

7 Bartel DP: MicroRNAs: genomics, biogenesis, mechanism, and function. Cell 2004;116:281-297.

8 Gu S, Jin L, Zhang F, Sarnow P, Kay MA: Biological basis for restriction of microRNA targets to the 3' untranslated region in mammalian mRNAs. Nat Struct Mol Biol 2009;16:144-150.

- Lujambio A, Lowe SW: The microcosmos of cancer. Nature 2012;482:347-355.

10 Han ZB, Yang Z, Chi Y, Zhang L, Wang Y, Ji Y, Wang J, Zhao H, Han ZC: MicroRNA-124 suppresses breast cancer cell growth and motility by targeting CD151. Cell Physiol Biochem 2013;31:823-832.

11 Li LQ Li XL, Wang L, Du WJ, Guo R, Liang HH, Liu X, Liang DS, Lu YJ, Shan HL, Jiang HC: Matrine inhibits breast cancer growth via miR-21/PTEN/Akt pathway in MCF-7 cells. Cell Physiol Biochem 2012;30:631641.

12 Zhang L, Yang L, Liu X, Chen W, Chang L, Chen L, Loera S, Chu P, Huang WC, Liu YR, Yen Y: MiR-657 promotes tumorigenesis in hepatocellular carcinoma by targeting transducin-like enhancer protein 1 through NF-kappaB pathways. Hepatology 2013;57:1919-1930.

13 Mott JL, Kobayashi S, Bronk SF, Gores GJ: mir-29 regulates Mcl-1 protein expression and apoptosis. Oncogene 2007;26:6133-6140.

14 Sachdeva M, Zhu S, Wu F, Wu H, Walia V, Kumar S, Elble R, Watabe K, Mo YY: p53 represses c-Myc through induction of the tumor suppressor miR-145. Proc Natl Acad Sci USA 2009;106:3207-3212.

-15 Strillacci A, Valerii MC, Sansone P, Caggiano C, Sgromo A, Vittori L, Fiorentino M, Poggioli G, Rizzello F, Campieri M, Spisni E: Loss of miR-101 expression promotes Wnt/beta-catenin signalling pathway activation and malignancy in colon cancer cells. J Pathol 2013;229:379-389.

16 Huang Y, Chen HC, Chiang CW, Yeh CT, Chen SJ, Chou CK: Identification of a two-layer regulatory network of proliferation-related microRNAs in hepatoma cells. Nucleic Acids Res 2012;40:10478-10493.

17 Varambally S, Cao Q, Mani RS, Shankar S, Wang X, Ateeq B, Laxman B, Cao X, Jing X, Ramnarayanan K, Brenner JC, Yu J, Kim JH, Han B, Tan P, Kumar-Sinha C, Lonigro RJ, Palanisamy N, Maher CA, Chinnaiyan AM: Genomic loss of microRNA-101 leads to overexpression of histone methyltransferase EZH2 in cancer. Science 2008;322:1695-1699.

18 Shan H, Zhang Y, Lu Y, Pan Z, Cai B, Wang N, Li X, Feng T, Hong Y, Yang B: Down-regulation of miR-133 and miR-590 contributes to nicotine-induced atrial remodelling in canines. Cardiovasc Res 2009;83:465-472. 
19 Lu Y, Zhang Y, Wang N, Pan Z, Gao X, Zhang F, Shan H, Luo X, Bai Y, Sun L, Song W, Xu C, Wang Z, Yang B: MicroRNA-328 contributes to adverse electrical remodeling in atrial fibrillation. Circulation 2010;122:2378-2387.

20 Zhao L, Sun Y, Hou Y, Peng Q Wang L, Luo H, Tang X, Zeng Z, Liu M: MiRNA expression analysis of cancerassociated fibroblasts and normal fibroblasts in breast cancer. Int J Biochem Cell Biol 2012;44:2051-2059.

21 Lee YS, Dutta A: MicroRNAs in cancer. Annu Rev Pathol 12009;4:199-227.

-22 Bao B, Ali S, Banerjee S, Wang Z, Logna F, Azmi AS, Kong D, Ahmad A, Li Y, Padhye S, Sarkar FH: Curcumin analogue CDF inhibits pancreatic tumor growth by switching on suppressor microRNAs and attenuating EZH2 expression. Cancer Res 2012;72:335-345.

-23 Carvalho J, van Grieken NC, Pereira PM, Sousa S, Tijssen M, Buffart TE, Diosdado B, Grabsch H, Santos MA, Meijer G, Seruca R, Carvalho B, Oliveira C: Lack of microRNA-101 causes E-cadherin functional deregulation through EZH2 up-regulation in intestinal gastric cancer. J Pathol 2012;228:31-44.

24 Su H, Yang JR, Xu T, Huang J, Xu L, Yuan Y, Zhuang SM: MicroRNA-101, down-regulated in hepatocellular carcinoma, promotes apoptosis and suppresses tumorigenicity. Cancer Res 2009;69:1135-1142.

25 He XP, Shao Y, Li XL, Xu W, Chen GS, Sun HH, Xu HC, Xu X, Tang D, Zheng XF, Xue YP, Huang GC, Sun WH: Downregulation of miR-101 in gastric cancer correlates with cyclooxygenase-2 overexpression and tumor growth. FEBS J 2012;279:4201-4212.

26 Ren G, Baritaki S, Marathe H, Feng J, Park S, Beach S, Bazeley PS, Beshir AB, Fenteany G, Mehra R, Daignault S, Al-Mulla F, Keller E, Bonavida B, de la Serna I, Yeung KC: Polycomb protein EZH2 regulates tumor invasion via the transcriptional repression of the metastasis suppressor RKIP in breast and prostate cancer. Cancer Res 2012;72:3091-3104.

-27 Sachdeva M, Wu H, Ru P, Hwang L, Trieu V, Mo YY: MicroRNA-101-mediated Akt activation and estrogenindependent growth. Oncogene 2011;30:822-831.

-28 Zhu QY, Liu Q Chen JX, Lan K, Ge BX: MicroRNA-101 targets MAPK phosphatase-1 to regulate the activation of MAPKs in macrophages. J Immunol 2010;185:7435-7442.

29 Verma A, Kambhampati S, Parmar S, Platanias LC: Jak family of kinases in cancer. Cancer Metastasis Rev 2003;22:423-434.

-30 Hedvat M, Huszar D, Herrmann A, Gozgit JM, Schroeder A, Sheehy A, Buettner R, Proia D, Kowolik CM, Xin H, Armstrong B, Bebernitz G, Weng S, Wang L, Ye M, McEachern K, Chen H, Morosini D, Bell K, Alimzhanov M, Ioannidis S, McCoon P, Cao ZA, Yu H, Jove R, Zinda M: The JAK2 inhibitor AZD1480 potently blocks Stat3 signaling and oncogenesis in solid tumors. Cancer Cell 2009;16:487-497.

-31 Quintas-Cardama A, Vaddi K, Liu P, Manshouri T, Li J, Scherle PA, Caulder E, Wen X, Li Y, Waeltz P, Rupar M, Burn T, Lo Y, Kelley J, Covington M, Shepard S, Rodgers JD, Haley P, Kantarjian H, Fridman JS, Verstovsek S: Preclinical characterization of the selective JAK1/2 inhibitor INCB018424: therapeutic implications for the treatment of myeloproliferative neoplasms. Blood 2010;115:3109-3117. 